\title{
The efficiency of the system tillage during of the cultivation crops
}

\author{
Yulia Semenikhina ${ }^{1 *}$, Sergey Kambulov ${ }^{1}$, Dmitriy Podlesniy ${ }^{2}$, Tamara Vladimirova $^{2}$, and \\ Sergey Belousov ${ }^{3}$ \\ ${ }^{1}$ Agricultural research center «Donskoy», 14, Lenina street, 347740, Zernograd, Russia \\ ${ }^{2}$ Don State Technical University, Gagarin sq., 1, 344003, Rostov-on-Don, Russia \\ ${ }^{3}$ Kuban State Agrarian University named after I.T. Trubilin, 13, Kalinina street, 350000, Krasnodar, \\ Russia
}

\begin{abstract}
When cultivating crops in arid conditions, special importance is attached to soil cultivation systems aimed at eliminating the deficiency of soil moisture. The main purpose of soil cultivation is to create an optimal soil structure, which is a multiphase system of solid, liquid and gaseous components that form soil fertility with a subsequent effect on the yield of agricultural crops. Various soil cultivation systems are used to form a favorable soil structure. The conservative cultivation system consists in the minimum impact on the soil (usually direct sowing) and with the preservation of plant residues on its surface. The relevance of the study is to identify the most effective system of soil cultivation. The study was carried out under the conditions of many years of stationary experience in legume crop rotation for 5 years. It was revealed that the conservative system of soil cultivation is effective and surpasses the traditional one in the following indicators: soil moisture is more by $14.2 \%$; the soil temperature is $2.6 \%$ lower; soil density is $3.48 \%$ higher. A stable increase in yield was also revealed: for winter wheat by $6.62 \%$, for spring barley by $8.09 \%$, for peas by $13.95 \%$ and for soybeans by $23.00 \%$.
\end{abstract}

\section{Introduction}

In the production of crop products, the leading role is assigned to soil-cultivating operations [1]. For climatically arid regions [2,3], particular importance is attached to soil cultivation systems aimed at eliminating the deficiency of soil moisture. Choosing a soil cultivation system, they focus on soil and climatic conditions, on the agrobiological characteristics of crops included in the crop rotation, on saving the natural potential of the soil, on the rational use of mineral fertilizers and chemical protection, etc. The tillage system [4] includes the following agrotechnological complexes of the main and surface tillage activities: tillage before sowing agricultural crops, mechanized care after sowing (cultivation) and tillage immediately after harvesting the crop with subsequent

\footnotetext{
${ }^{*}$ Corresponding author: semenixina1982@,mail.ru
} 
preparation of the soil for sowing. It is the preparation of the soil for sowing that is the main one and differs from the surface one both in depth and in the method of impact on the soil, depending on the working bodies of agricultural machines. The main purpose is to create an optimal soil structure [5,6], which is a multiphase system of solid, liquid and gaseous components. These phases are mobile in the soil space and, over time, self-organizing the architecture of the soil skeleton, consisting of interconnected soil aggregates (solid phase) and macro-micropores (liquid and gaseous phase). The result of this interaction ensures the movement of soil moisture, nutrients and gases, and also forms a habitat for microorganisms.

The optimal structure ensures soil quality and is a fundamental property of soil fertility that can influence the growth and productivity of agricultural crops [7]. To form a favorable soil structure, various systems of soil cultivation are used: from traditional to conservative. The choice depends on soil and climatic conditions, on crop rotation, on the weediness of crops, on the granulometric composition of the soil, on erosion factors, etc.

The traditional [8] processing system is based on the following technological operations: loosening, wrapping, crumbling lumps, mixing, leveling, compaction, cutting weeds, creating furrows and ridges, and stubble sealing. In modern agricultural production, multifunctional tillage machines are used, which combine several such operations in one pass. Which is economically and ecologically justified, since energy and labor costs are reduced, the time required for field work is reduced, and the harmful effect on the soil is reduced and the risks of its overcompaction are reduced. The traditional soil cultivation system most often has a deep impact on the soil and solves the problem of saturating the soil with atmospheric moisture by forming a hygroscopic structure. The soil, after the intensive influence of tillage tools on it, forms macropores between soil aggregates and thereby acquires hydraulic conductivity throughout the soil profile, contributing to an increase in soil moisture $[9,10]$. However, during the dry period, when the air temperature remains high for a long time, evapotranspiration also increases. Therefore, the operation of deep tillage is completed by compaction and mulching to form a near-surface layer that prevents the evaporation of soil moisture.

The conservative system of tillage [11] differs from the traditional one in its essence. The number of agro-technological operations is reduced to a minimum, while a prerequisite is the preservation of plant residues of the previous crop to cover the field surface with an area of $30 \%$ or more [12]. This type of cultivation also includes mechanized surface cultivation, when the cultivation depth is minimal (up to $10 \mathrm{~cm}$ ) or direct sowing, when no preparatory tillage is performed before sowing. At the same time, the long-term use of direct sowing in the cultivation of agricultural crops on the same plot is considered to be a No-Till (NT) technology [13]. The challenge for the latest technology is to preserve soil moisture.

For areas with a dry and long period (summer), conservative cultivation is preferable due to the fact that the least impact on the soil, both in depth and in the number of passes, allows the structure to form in a natural way, and the presence of plant residues forms a protective dense layer that prevents evaporation soil moisture, soil overheating and reduces erosion processes.

Therefore, it is relevant and practically significant to study the traditional and conservative systems of soil cultivation, contributing to the favorable formation of hydrothermal soil conditions, the optimal structure (density) of the soil and stable productivity of agricultural crops.

\section{Materials and methods}


When using traditional and conservative systems of soil cultivation, the influence of various methods of basic soil cultivation on the dynamics of the hydrothermal regime of the soil, on soil density and crop yield was studied in detail. Table 1 shows the methods of tillage and the result of their impact on the soil.

Table 1. Characteristics of soil cultivation and the results of its impact .

\begin{tabular}{|c|c|c|}
\hline Tillage system & $\begin{array}{l}\text { The main method of } \\
\text { tillage }\end{array}$ & The result of impact on the soil \\
\hline \multirow{3}{*}{ Traditional system } & Shallow tillage & $\begin{array}{l}\text { Layer-by-layer loosening to a depth of } 14-16 \mathrm{~cm} \text { with } \\
\text { simultaneous pruning of weeds, leveling, compaction } \\
\text { and mulching of the surface layer. }\end{array}$ \\
\hline & $\begin{array}{l}\text { layer-by-layer } \\
\text { tillage }\end{array}$ & $\begin{array}{l}\text { Mouldboard-free layer-by-layer loosening to a depth } \\
\text { of } 20-25 \mathrm{~cm} \text { with simultaneous pruning of weeds, } \\
\text { leveling, and compaction of the surface layer. }\end{array}$ \\
\hline & $\begin{array}{l}\text { Dump method of } \\
\text { tillage }\end{array}$ & $\begin{array}{l}\text { Loosening to a depth of } 20-25 \mathrm{~cm} \text { with a turnover of } \\
\text { the soil layer }\end{array}$ \\
\hline \multirow{2}{*}{$\begin{array}{l}\text { Conservative } \\
\text { system }\end{array}$} & Surface tillage & $\begin{array}{l}\text { Surface loosening and weed control, chopping up the } \\
\text { crop residues of the previous crop }\end{array}$ \\
\hline & $\begin{array}{l}\text { No tillage (No-till } \\
\text { technology } \\
\text { principle) }\end{array}$ & $\begin{array}{l}\text { Direct sowing of grain and / or leguminous crops in a } \\
\text { row method with simultaneous application of } \\
\text { fertilizers using disc coulters to the seeding depth. }\end{array}$ \\
\hline
\end{tabular}

The research was carried out under the conditions of long-term stationary experience in legume crop rotation for 5 years. The repetition is threefold. Crops cultivated are winter wheat, spring barley, peas and soybeans. The soil of the experimental site is represented by ordinary carbonate heavy loamy chernozem. Content of humus in the arable layer of soil: $3.2 \%$; pH - 6.8-7.1; P2O5 - 18.8-22.7 mg/ kg; K2O - 336-360 mg / kg of soil. Weather conditions during the growing season of crops differed in the amount of precipitation and air temperature. So, in the 2014/2015 agricultural year, the amount of precipitation and the average daily air temperature were higher than the average annual by $114 \%$ and $113 \%$, respectively. In the 2015/2016 agricultural year, precipitation fell unevenly and in general, their amount was $104 \%$ of the climatic norm, while the average daily temperature was $121 \%$ of the multiyear norm. In the 2016/2017 agricultural year, the amount of precipitation and the average daily air temperature were $124 \%$ and $110 \%$ higher than the long-term average, respectively. In the 2017/2018 agricultural year, precipitation fell unevenly over the seasons, their sum was $102 \%$ of the norm, and the average monthly air temperature was higher than the average annual (by 117\%). In the 2018/2019 agricultural year, there was a slight excess of precipitation (106\% of the multi-year norm) and an increased temperature regime of the air (127\% of the norm). When studying the soil climate, the air temperature was taken into account, since this indicator has a significant effect on evapotranspiration $[14,15]$. The study of the dynamics of hydrothermal conditions due to the use of various methods of soil cultivation was carried out using autonomous field weather stations Watch Dog 1400 (Figure 1).

The soil moisture and temperature sensors were placed in the soil horizon at a depth of $30 \mathrm{~cm}$. The results of the indicators were recorded in one hour increments and were automatically recorded on the internal memory of the Watch Dog 1400 weather station recorder. Once a month, the data were retrieved, brought to average daily values and processed using mathematical statistics. 


\section{Registrar}
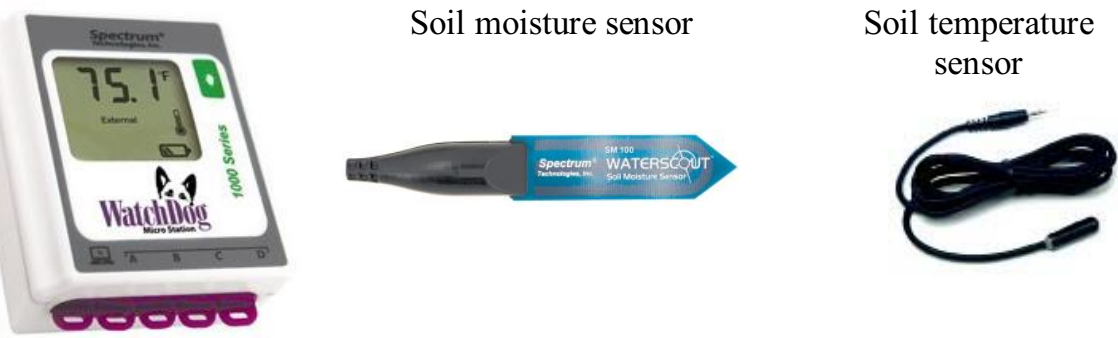

Fig. 1. Watchdog field weather station: 1400 Micro recorder, moisture and soil temperature sensors.

To study the effect of the tillage system on soil density, samples were taken from the meter layer and analyzed. The yield of cultivated crops was determined using a combine method.

\section{Research results}

Research and analysis of long-term data on soil moisture and temperature in the soil horizon of $30 \mathrm{~cm}$ did not reveal significant differences between cultivated crops. The most significant impact on the soil climate was exerted by the soil cultivation systems, therefore, the results of the statistical analysis of the study of hydrothermal dynamics (soil moisture and temperature) on average for 5 years are presented in Table 2.

Table 2. Statistical analysis of the results of the study of moisture $(\%)$ and soil temperature $\left({ }^{\circ} \mathrm{C}\right)$.

\begin{tabular}{|c|c|c|c|c|c|c|c|}
\hline 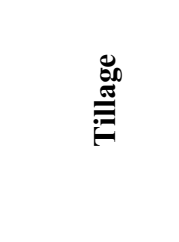 & 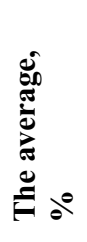 & $\stackrel{\partial}{\stackrel{\partial}{E}}$ & 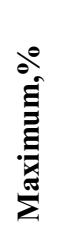 & 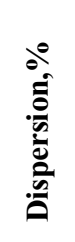 & 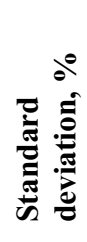 & 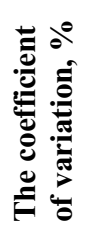 & 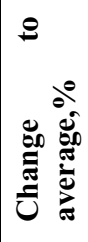 \\
\hline \multicolumn{8}{|c|}{ Dynamics of soil moisture, $\%$} \\
\hline Traditional & 39.9 & 6.7 & 64.5 & 431.3 & 20.8 & 52.1 & 85.8 \\
\hline Conservative & 46.5 & 7.4 & 62.2 & 339.7 & 18.4 & 39.6 & 100.0 \\
\hline \multicolumn{8}{|c|}{ Dynamics of soil temperature, ${ }^{\circ} \mathrm{C}$} \\
\hline Traditional & 8.0 & 1.3 & 25.4 & 58.8 & 7.7 & 95.0 & 102.6 \\
\hline Conservative & 78 & 1.7 & 24.1 & 49.6 & 7.0 & 89.7 & $\overline{100.0}$ \\
\hline
\end{tabular}

Analysis of the data obtained indicates the advantage of a conservative processing system. Since the changes to the average for soil moisture are $14.2 \%$ higher than the soil moisture in the traditional system. At the same time, the soil temperature with the conservative system is cooled by $2.6 \%$ in comparison with traditional cultivation. At the same time, the performed correlation analysis revealed a moderate negative relationship between the ambient air humidity and soil moisture in the traditional system of -0.49 and with the conservative -0.41 . The general conclusion confirms the ability of the soil structure in an undisturbed state to accumulate and retain soil moisture, that is, a decrease in evapotranspiration is inherent in a conservative system of soil cultivation and the naturelike formation of soil structure from this position is preferable. Thus, the application of a 
conservative soil cultivation system for the arid zone is the most urgent. The study of soil density over 5 years, depending on the soil cultivation system, are presented in Table 3.

Table 3. Results of the study of soil density depending on the soil cultivation system, $\mathrm{g} / \mathrm{cm} 3$.

\begin{tabular}{|c|c|c|c|c|c|c|c|}
\hline \multirow{2}{*}{$\begin{array}{l}\text { Tillage } \\
\text { system }\end{array}$} & \multicolumn{5}{|c|}{ Years of research } & \multirow{2}{*}{$\begin{array}{c}\text { The } \\
\text { average, }\end{array}$} & \multirow{2}{*}{$\begin{array}{c}\text { Change to th } \\
\text { average, \% }\end{array}$} \\
\hline & 2015 & 2016 & 2017 & 2018 & 2019 & & \\
\hline Traditional & 1.13 & 1.16 & 1.14 & 1.15 & 1.16 & 1.15 & 100.00 \\
\hline Conservative & 1.19 & 1.20 & 1.17 & 1.18 & 1.19 & 1.19 & 103.48 \\
\hline
\end{tabular}

Analysis of the data obtained indicates that the conservative system of soil cultivation forms a denser soil structure by $3.48 \%$ than the traditional one. Thus, the rejection of the constant loosening of the soil formed its dense composition due to the spatial and temporal location of soil aggregates and a decrease in the number of micro- and macropores between them. The most significant criterion for the efficiency of the soil cultivation system is the indicator of the yield of agricultural crops, which directly depends on the moisture supply of the soil. Long-term studies on the influence of traditional and conservative soil cultivation systems on the yield of cereal crops and legumes are presented in Table 4. Analysis of the obtained averaged data for a specific crop and for years, depending on the soil cultivation system, revealed an increase in yield with a conservative soil cultivation system compared to the traditional one for winter wheat by $6.62 \%$, for spring barley by $8.09 \%$, for peas by $13,95 \%$, for soybeans by $23.00 \%$. From these data, it follows that legumes have the greatest increase in yield than cereals, which requires further research.

Table 4. Research results on the yield of grain crops depending on the soil cultivation system, t/ha.

\begin{tabular}{|c|c|c|c|c|c|c|c|}
\hline \multirow[t]{2}{*}{ Tillage system } & \multicolumn{5}{|c|}{ Years of research } & \multirow{2}{*}{$\begin{array}{c}\text { The } \\
\text { average. }\end{array}$} & \multirow{2}{*}{$\begin{array}{c}\text { Change to the } \\
\text { average. } \%\end{array}$} \\
\hline & 2015 & 2016 & 2017 & 2018 & 2019 & & \\
\hline \multicolumn{8}{|c|}{ Winter wheat } \\
\hline Traditional & 5.36 & 4.41 & 7.73 & 5.87 & 5.01 & 5.68 & 100.00 \\
\hline Conservative & 6.22 & 4.71 & 7.85 & 6.05 & 5.43 & 6.05 & 106.62 \\
\hline \multicolumn{8}{|c|}{ Spring barley } \\
\hline Traditional & 2.36 & 2.11 & 5.04 & 2.63 & 3.18 & 3.06 & 100.00 \\
\hline Conservative & 2.55 & 2.29 & 5.44 & 2.85 & 3.43 & 3.31 & 108.09 \\
\hline \multicolumn{8}{|c|}{ Peas } \\
\hline Traditional & 2.39 & 2.50 & 2.59 & 2.20 & 2.65 & 2.47 & 100.00 \\
\hline Conservative & 2.72 & 2.85 & 2.95 & 2.51 & 3.02 & 2.81 & 113.95 \\
\hline \multicolumn{8}{|c|}{ Soybean } \\
\hline Traditional & 1.69 & 1.09 & 2.93 & 2.84 & 1.84 & 2.08 & 100.00 \\
\hline Conservative & 2.16 & 1.86 & 3.31 & 3.18 & 2.27 & 2.56 & 123.00 \\
\hline
\end{tabular}

In general, the weather conditions forming a shortage of soil moisture due to insufficient atmospheric precipitation and its intensive evaporation are uncontrollable factors, therefore, one can only adapt to them. The most effective and efficient way to do this is the conservative system of tillage for the zone with insufficient and unstable moisture. Moreover, the yield of agricultural crops directly depends on soil moisture, or rather on its availability during the growing season of plants in sufficient quantities. In this case, the conservative processing system is more effective than the traditional one.

\section{Conclusion}

Long-term studies on the influence of the soil cultivation system on the hydrothermal regime of the soil, on the density of the soil and on the yield of agricultural crops during 
their cultivation have been carried out. The obtained results of the study indicate that the conservative system of soil cultivation provides a stable increase in yield compared to traditional for winter wheat by $6.62 \%$, for spring barley by $8.09 \%$, for peas by $13.95 \%$ and for soybeans. by $23.00 \%$. With the same processing system, soil moisture remains intact and exceeds the traditional processing system by $14.2 \%$, and also contributes to a decrease in soil temperature by $2.6 \%$. A slight increase in soil density by $3.48 \%$ when using a conservative tillage system did not reveal a detrimental effect on its structure. This allows in conclusion to conclude that a conservative processing system is effective. As a result of its application, a soil structure is formed capable of accumulating soil moisture and reducing evapotranspiration. At the same time, plants during the growing season do not experience extreme drought and are able to form high and stable productivity.

\section{References}

1. Y. Dang, A. Balzer, M. Crawford, et al., Environmental Science and Pollution Research, 25(2), 1000-1015 (2018) https://doi.org/10.1007/s11356-017-8937-1.

2. A. Shekhar, C.A. Shapiro, Soil and Tillage Research, 193, 161-170, (2019) https://doi.org/10.1016/j.still.2019.06.004

3. Y.A. Semenikhina, S.I. Kambulov, G.G. Parkhomenko, A.A. Boyko, S.V. Ponomareva, S.V. Shvedova, A.F. Koltsov, E.O. Tsybenko, E3S Web of Conferences. XIII International Scientific and Practical Conference "State and Prospects for the Development of Agribusiness - INTERAGROMASH 2020” Rostov-on-Don, 09008, (2020), https://doi.org/10.1051/e3sconf/202017509008

4. M. Kribaa, V. Hallaire, P. Curmi, R. Lahmar, Soil and Tillage Research, 60, 43-53, (2011) https://doi.org/10.1016/S0167-1987(01)00171-4

5. X. Peng, R. Horn, P. Hallett, Soil and Tillage Research, 146 (A) , 1-3, (2015) doi.org/10.1016/j.still.2014.10.017

6. G.G. Parkhomenko, S.I. Kambulov, A.V. Olshevskaya, et all., IOP Conference Series: Earth and Environmental Science (2019) https://doi.org/10.1088/1755$1315 / 403 / 1 / 012144$

7. Y. Abbaspour-Gilandeh, R.Sedghi, Journal of Terramechanics, Predicting soil fragmentation during tillage operation using fuzzy logic approach, 57, 61-69, (2015) doi.org/10.1016/j.jterra.2014.12.002

8. K.U. Totsche, W. Amelung, M.H. Gerzabek, et al., J. Plant Nutr. Soil Sci, 181(1), 133, (2017) DOI: 10.1002/jpln.201600451.

9. D. Kool, B. Tong, Z. Tian, et al., Soil and Tillage Research, 193, 95-100, (2019) https://doi.org/10.1016/j.still.2019.05.020

10. K. Adhikari, A.E. Hartemink, Geoderma, 262, 101-111 (2016) doi: 10.1016/j.geoderma.2015.08.009

11. R.J.Cooper, Z.Q.Hama-Aziz, K.M.Hiscock, et al., Soil and Tillage Research, 202, 104648, (2020) https://doi.org/10.1016/j.still.2020.104648

12. Z. Du, T. Ren, C. Hu, Soil and Tillage Research, 146(A), 26-31, (2015) doi.org/10.1016/j.still.2014.08.012

13. H. Blanco-Canqui, S.J. Ruis, Geoderma, 326, 164-200 (2018) https://doi.org/10.1016/j.geoderma.2018.03.011

14. G. T. Getahun, T. Kätterer, L. J. Munkholm, Soil and Tillage Research, 184, 62-67, (2018) https://doi.org/10.1016/j.still.2018.06.007

15. D. Helman, D.J. Bonfil, I. Lensky, Crop RS-Met: Agricultural Water Management, 211, 210-219 (2019) https://doi.org/10.1016/j.agwat.2018.09.043 